\title{
Physico-chemical properties of Moringa oleifera seed oil enzymatically interesterified with palm stearin and palm kernel oil and its potential application in food
}

\begin{abstract}
Background: High oleic acid Moringa oleifera seed oil (MoO) has been rarely applied in food products due to the low melting point and lack of plasticity. Enzymatic interesterification (EIE) of $\mathrm{MoO}$ with palm stearin (PS) and palm kernel oil (PKO) could yield harder fat stocks that may impart desirable nutritional and physical properties. Results: Blends of $\mathrm{MoO}$ and PS or PKO were examined for triacylglycerol (TAG) composition, thermal properties and solid fat content (SFC). EIE caused rearrangement of TAGs, reduction of U3 and increase of U2 S in MoO/PS blends while reduction of $\mathrm{U} 3$ and S3 following increase of S2 U and U2 S in $\mathrm{MoO} / \mathrm{PKO}$ blends (U, unsaturated and S, saturated fatty acids). SFC measurements revealed a wide range of plasticity, enhancements of spreadability, mouthfeel and cooling effect for interesterified MoO/PS, indicating the possible application of these blends in margarines. However, interesterified $\mathrm{MoO} / \mathrm{PKO}$ was not suitable in margarine application, while icecream may be formulated from these blends. A soft margarine formulated from MoO/PS 70:30 revealed high oxidative stability during 8 weeks storage with no significant changes in peroxide and p-anisidine values. Conclusion: EIE of fats with $\mathrm{MoO}$ allowed nutritional and oxidative stable plastic fats to be obtained, suitable for possible use in industrial food applications.
\end{abstract}

Keyword: Moringa oleifera seed oil; Enzymatic interesterification; Oleic acid; Palm kernel oil; Palm stearin; Plastic fats 